\title{
Discursos de cirurgiões-dentistas do Programa Saúde da Família: crise e mudanca de habitus na Saúde Pública
}

Mônica Campos Chaves ${ }^{1}$

Alcides Silva de Miranda²

CHAVES, M.C.; MIRANDA, A.S. Discourse among dentists within the Family Healthcare Program: crisis and change of habitus within public health. Interface - Comunic., Saúde, Educ., v.12, n.24, p.153-67, jan./mar. 2008.

This paper analyzes the meaning of discourse among dentists relating to their perceptions of their place and professional activities within Family Healthcare Program services in municipalities in the metropolitan area of Fortaleza, CE. This was a qualitative study based on interviews with key informants, which used a technique derived from the content analysis method and a dialectic approach. The thematic content showed a perception of contradictions between the dentists' initial motivations and expectations from choices made and their professional identification; their ideation regarding their professional activities; the process of training and graduation; and the real conditions of integration, professional activities and working practices within public primary healthcare services. It denotes a crisis of a certain professional habitus, because of their integration into a new context of salaried work and service provision within the public sphere, differing from their initial expectations and ideation of liberal professional activities.

Key words: Social perception. Professional practice. Community dentistry. Education in dentistry. Family healthcare.
No artigo são analisados os significados de discursos proferidos por cirurgiõesdentistas, que tratam das percepções sobre a própria inserção e atuação profissionais em serviços do Programa de Saúde da Família de municípios da área metropolitana de Fortaleza/CE. Trata-se de um estudo qualitativo, com base em entrevistas com informantes-chave, utilizando técnica derivada do método de "Análise de Conteúdo" e abordagem dialética. Os conteúdos temáticos evidenciam a percepção de contradições entre as motivações e expectativas iniciais de escolha e identificação profissionais; as ideações sobre a atuação profissional; o processo de formação na graduação; e as condições reais de inserção, atuação profissional e práticas de trabalho em serviços públicos de Atenção Básica à Saúde. Denota-se a crise de um determinado habitus profissional, em razão de sua inserção em um novo contexto de trabalho assalariado e prestação de serviços na esfera pública, diverso da expectativa e ideação iniciais de uma atuação profissional-liberal.

Palavras-chave: Percepção social. Prática profissional. Odontologia comunitária. Educação em odontologia. Saúde da Família.
${ }^{1}$ Cirurgiã-dentista. Secretaria Municipal de Saúde de Fortaleza. Rua Prof. Lino Encarnação, 1379 Parquelândia Fortaleza CE 60.450-230 moni_campos@hotmail.com 2 Médico. Universidade Federal do Ceará. 


\section{Introdução}

O chamado "Programa Saúde da Família" (PSF) tornou-se a marca institucional e a expressão normativa de uma estratégia programática oriunda do setor governamental de Saúde, que vem sendo progressivamente implementada desde 1994 em todo o Brasil. Uma vez conformadas as suas diretrizes normativas nacionais, o propósito primordial dessa estratégia tem sido ampliar o acesso e estabelecer um determinado modelamento da rede de sistemas e serviços de Atenção Básica à Saúde, a partir do provimento de um modo específico de financiamento (fração variável do Piso da Assistência Básica) e de apoio logístico intergovernamental.

Uma das principais diretrizes normativas do PSF refere-se ao trabalho interdisciplinar de equipes multiprofissionais em Unidades Básicas de Saúde da Família (UBASF), responsáveis pelo acompanhamento de um número definido de famílias que vivem em uma área geográfica delimitada (conceito logístico de adscrição de território). Neste âmbito comunitário e nos serviços locais, as equipes do PSF devem atuar em ações de promoção, proteção e recuperação da saúde individual e coletiva (Brasil, 2005).

Em sua complexidade, o PSF está conformado por uma estratégia programática dialeticamente estruturada e estruturante, instituída e instituinte. É estruturada com base em diversos determinantes sociais, notadamente aqueles decorrentes das políticas de governo, que se interpõem em uma pluralidade de instâncias e dinâmicas de poder, típicas dos sistemas institucionalizados de ação. É instituída em razão de normas, prescrições e comportamentos regrados (Weber, 1996) da parte de seus atores institucionais, individuais e coletivos. É instituinte em razão das ações intencionais da parte dos diversos atores institucionais de seu entorno, do exercício e das graduações de poder estabelecidos entre os mesmos, das dinâmicas de margens de autonomia de cada um e das interações e mediações políticas resultantes. É estruturante de uma determinada modelagem para as políticas de "Atenção à Saúde" de nível primário e de âmbito local, distinta das anteriores. Essa modelagem é consubstanciada em inovações e combinações tecnológicas afins, que produzem novas dinâmicas e práticas de trabalho, que constituem novos perfis profissionais e comunidades de práticas em seu entorno. Em suma, essa estratégia programática é derivada de uma política setorial de governo, que está sob constantes tensionamentos dialéticos, permeada de contradições e dependente de mediações políticas que adquirem uma materialidade singular em cada caso e experiência; para além do seu marco referencial jurídico-normativo, de sua logística sistêmica ou de seu contexto funcional.

Dentre os agentes institucionais que atuam no entorno do PSF estão os profissionais de nível superior, trabalhadores e prestadores de serviços que, na maioria dos casos, ainda não possuem vínculo empregatício permanente na esfera pública (Brasil, 2005; Girardi \& Carvalho, 2004). Desse contingente de nível superior, de início, eram admitidos preferencialmente, no PSF, os profissionais médicos e enfermeiros. Mas, sobretudo a partir de 2001, acentuou-se a admissão de cirurgiõesdentistas, à medida que houve um incremento da programação de recursos e ações para as políticas e estratégias de Saúde Bucal. A partir de então, houve um aumento significativo na inserção de Equipes de Saúde Bucal (ESB) no PSF, compostas por cirurgiões-dentistas e técnicos ou auxiliares de nível médio.

De acordo com os dados divulgados em agosto de 2006 pelo Departamento de Atenção Básica (DAB/SAS) do Ministério da Saúde (Brasil, 2006), entre os meses de janeiro de 2001 e dezembro de 2005, o número total de Equipes do PSF registradas no Sistema de Informações de Atenção Básica (SIAB) aumentou de 13.200 para 24.600 (incremento em torno de $80 \%$ ). O número específico de ESB registradas no SIAB aumentou de 2.248 para 13.269 unidades (incremento de quase $600 \%$ ); uma proporção que variou de $17 \%$ para $54 \%$ de ESB em relação ao número total de equipes do PSF. Enquanto, no mesmo período, a estimativa da população brasileira adscrita em áreas sob a responsabilidade de equipes do PSF cresceu de 22,1 \% para $34 \%$ (chegando a 52,8 \% na região nordestina), a população adscrita por ESB cresceu de 3,7 \% para 18,3\%. É importante salientar que o registro da implantação de uma nova equipe de Saúde Bucal no SIAB não significou necessariamente a abertura de um novo posto de trabalho para cirurgiões-dentistas, pois, em muitos 
casos, implicou o aumento de carga horária para profissionais já contratados. De qualquer modo, esses dados divulgados permitem estimar que, no referido período, houve um significativo aumento de postos de trabalho para cirurgiões-dentistas no PSF, além de contratações para outros programas nacionais, estaduais e municipais de Saúde Bucal implantados desde então.

Tal incremento quantitativo na inserção de profissionais de odontologia em serviços de Atenção Básica pode ser considerado um fenômeno recente e original. Notadamente por sua nova conformação social, pela existência de um novo nicho de oferta e atração de empregos na esfera pública e pela utilização de uma força de trabalho qualificada, com uma formação social típica (Marx, 1984), em função de um novo contexto organizativo e laboral. Mas trata-se, também, de um fenômeno original, nos termos de um novo cenário institucional e normativo para a atuação profissional e as práticas de trabalho dos cirurgiões-dentistas, que tende a determinar e/ou condicionar mudanças substanciais no seu modus operandi, em seus gradientes de poder (político, técnico, administrativo) e margens de autonomia. O que pode implicar novas significações e significados para esses modos de atuação profissional e práticas de trabalho, da parte de seus protagonistas.

Quando um determinado grupo social estabelece uma identificação mútua no modo sistemático de pensar e agir, no estilo e nos interesses, desenvolvendo um senso prático em comum; torna-se possível caracterizá-lo pelo seu perfil de identidades, em termos de regularidades identificáveis e apreensíveis. Tal perfil é o que Bourdieu (1996) define como um habitus, um princípio gerador que identifica as características intrínsecas e relacionais de uma posição, de práticas distintas e distintivas. A noção de habitus é caracterizada como um sistema de disposições duráveis, princípios geradores e estruturantes de práticas e de representações que podem ser objetivamente reguladas. Assim, se cada agente social dispõe de uma estrutura mental, uma vivência com percepções e representações únicas, um estilo de vida singular e opiniões próprias que lhes definem predisposições e unidades de estilo, quando essas características conformam um modo comum de pensar e agir, engendram um habitus. Dialeticamente estruturante e estruturada (em termos de sua formação social), tal categoria deve ser considerada essencialmente em sua dimensão relacional.

Um habitus engendrado em um grupo social, como o da categoria profissional de cirurgióesdentistas, constitui-se de expressões de uma espécie de "senso prático comum". Há um conjunto de características e atributos determinados objetivamente pela identificação de interesses ou propósitos afins, mas dependente de uma dinâmica interativa de capitais e exercício efetivo de poder e do tensionamento de margens de autonomia no campo profissional (Bourdieu, 1996). Há, ainda, um conjunto de características e atributos constituídos subjetivamente pela identificação e compartilhamento de crenças, valores, linguagens, ritos, interpretações, explicações etc. O que possibilitaria um escopo de investigação muito abrangente, um cabedal de identificações plausíveis, mesmo para um estudo exploratório. Optou-se, então, por ressaltar os temas recorrentes, com base em um perfil de identidades e contradições entre expectativas, o sentido prescritivo das normas (de ensino, programáticas) e as experiências profissionais vividas em ambas as esferas de trabalho e de atuação profissional.

Considerando-se os processos de implantação de Equipes de Saúde Bucal no PSF, em seus casos concretos e experiências singulares, como analisar os fenômenos de determinação e/ou (re)condicionamento na atuação profissional dos cirurgiões-dentistas, em suas relações e práticas de trabalho? Mais especificamente, como esses profissionais expressariam as suas expectativas e percepções acerca de sua atuação profissional e práticas de trabalho neste novo contexto do PSF?

Embora se trate de um fenômeno mais recente, já são freqüentes, na literatura científica nacional, as pesquisas de natureza qualitativa sobre as percepções e representações de cirurgiões-dentistas acerca de seu processo de trabalho e atuação profissional.

Nesse caso, predominam os estudos sobre representações sociais de cirurgiões-dentistas, como, por exemplo, sobre riscos profissionais e biossegurança do trabalho (Rodrigues, Domingues Sobrinho \& Silva, 2005, 2004), sobre a atenção odontológica a grupos específicos (Costa, Saliba \& Moreira, 2002), mas também existem estudos deste tipo sobre a atuação profissional de cirurgiões-dentistas em serviços públicos de saúde (Mellin \& Tanaka, 2003). 
Em outro tipo de enfoque, Moreira, Nuto e Nations (2004) usaram uma abordagem antropológica para estudar as percepções e crenças em Saúde Bucal dos habitantes de uma comunidade urbana de Fortaleza/CE, buscando, assim, compreender a comunicação clínica entre acadêmicos de odontologia e seus pacientes, com a finalidade de sugerir melhoras para a humanização da prática odontológica. Com base no estudo, esses autores concluem que os modelos explicativos científicos e populares em Saúde Bucal no local estudado são diferentes e, muitas vezes, antagônicos, dificultando a interação entre dentistas e usuários.

Em se tratando da análise mais específica das práticas odontológicas em Unidades Básicas de Saúde, Pereira, Pereira e Assis (2003) realizaram um estudo exploratório com a utilização da metodologia de "Análise de Conteúdo" (Bardin, 1977), entrevistando cirurgiões-dentistas do sistema municipal de saúde de Feira de Santana/BA. Esses autores concluem que os cirurgiões-dentistas persistem numa prática profissional pautada no modelo da odontologia tradicional, privilegiando ações individuais, autônomas, curativas e tecnicistas.

Estudos dessa natureza podem contribuir para uma maior compreensão sobre a problemática apresentada, assim como para a geração de novas premissas de investigação.

\section{Metodologia}

Foi realizado um estudo de natureza qualitativa, tomando-se por base a "Análise de Conteúdo" (Bardin, 1977) e a abordagem dialética (Minayo, 2002, 1996), sobre os significados de discursos práticos (Habermas, 1987) emitidos por cirurgiões-dentistas que atuavam profissionalmente em Unidades Básicas de Saúde da Família (UBASF) de quatro municípios-satélites da área metropolitana de Fortaleza, capital do Estado do Ceará, região nordeste do Brasil.

A amostra intencional dos municípios, das suas respectivas UBASF e dos cirurgiões-dentistas incluídos como informantes-chave no estudo (Quadro 1) foi estabelecida valendo-se dos seguintes critérios:

1 Municípios de maior proximidade geográfica com a capital do estado, o que, além de ter facilitado a coleta das informações, tornou o estudo economicamente viável.

2 Em cada município selecionado, foram escolhidas as UBASF com equipes de Saúde Bucal e os cirurgiões-dentistas que atuavam profissionalmente há mais tempo, com o corte mínimo de dois anos.

A capital Fortaleza foi excluída da amostragem porque, na ocasião do estudo, o município não possuía equipes de Saúde Bucal cadastradas no PSF.

Critérios de exaustividade, representatividade, homogeneidade, pertinência e recorrência de conteúdos temáticos definiram o limite de 11 entrevistas.

Quadro 1. Descrição dos municípios, Unidades Básicas de Saúde da Família e quantitativo de informanteschave incluídos na amostra intencional e entrevistados no estudo.

\begin{tabular}{|l|l|c|}
\hline \multicolumn{1}{|c|}{ Municípios } & \multicolumn{1}{c|}{ UBASF } & $\begin{array}{c}\text { Número de } \\
\text { informantes-chave }\end{array}$ \\
\hline Maracanaú & $\begin{array}{l}\text { Alarico Leite, Colônia Antonio Justo, Elias Boutola, Mucunã, } \\
\text { JPA e Alto Alegre. }\end{array}$ & 06 \\
\hline Maranguape & Jubaia & 01 \\
\hline Caucaia & Nova Metrópole, Joaquim Braga da Rocha e Sítios Novos. & 03 \\
\hline Pacatuva & Sede & 01 \\
\hline Total de entrevistados & & 11 \\
\hline
\end{tabular}


A sistemática utilizada para processamento e análise das informações coletadas nas entrevistas seguiu a seqüência definida pelo método de "Análise de Conteúdo", do tipo "Categorial e Temática" (Bardin, 1977):

1 Pré-análise: leitura flutuante das entrevistas transcritas, com classificação manual e ordenação prévia de enunciados intactos (sintagmas analíticos);

2 Constituição e exploração de um corpus de leitura intertextual: edição de enunciados considerados significativos, de acordo com a pertinência, equivalência, exaustividade, representatividade e homogeneidade para com os temas previstos no roteiro ou surgidos espontaneamente no decorrer das entrevistas;

3 Identificação de unidades de significado e de unidades de contexto: unidades textuais de palavras, linhas e parágrafos oriundas dos enunciados escolhidos, sendo identificadas por conteúdos temáticos manifestos segundo reagrupamentos analógicos;

4 Análise e explicação de significados: explicação dos significados evidenciados nos discursos, com base em categorias de análise definidas por referência aos conteúdos temáticos e seus contextos factuais.

Convém ressaltar que, se a "Análise de Conteúdo" é apresentada originalmente como uma metodologia com tratamento de análise tipicamente fenomenológico (Bardin, 1977), neste estudo houve também o evidenciamento de alguns significados contraditórios e agregou-se uma abordagem dialética de análise e síntese temática (Minayo, 2002, 1996).

O estudo obedeceu às regras estabelecidas pela Resolução 196/96 do Conselho Nacional de Saúde (Brasil, 2003), que estabelece normas para os procedimentos éticos em pesquisas envolvendo seres humanos, tendo sido aprovado pelo Comitê de Ética em Pesquisa da Universidade Estadual do Ceará. Todos os entrevistados foram informados dos objetivos do estudo, ocasião em que lhes foi assegurado o anonimato e a possibilidade de desistência, e assinaram um termo de consentimento.

\section{Principais resultados}

Os principais conteúdos temáticos, evidenciados na análise do estudo, referem-se aos discursos práticos sobre a formação profissional na graduação de Odontologia, as ofertas e restrições do mercado de trabalho e as condições para o exercício das atividades profissionais nas esferas pública e privada, temas que revelam significados sobre a migração voluntária ou exílio forçado, desde um perfil profissional liberal ou assalariado, na esfera privada, para um novo perfil de trabalho assalariado, sem vínculo empregatício ou garantias trabalhistas, na esfera pública. São evidenciadas conotações significativas sobre expectativas e constatações advindas das mudanças no processo e nas condições de trabalho, da prática liberal ao assalariamento (seja na esfera pública ou privada); e sobre a decorrente (re)constituição da identidade profissional após a transição para um novo âmbito de atuação profissional, sob a égide de uma política pública de Saúde Bucal e de uma estratégia programática típica da Atenção Básica, o PSF.

\section{Escolha profissional, processo de formação na graduação, mercado e condições de trabalho dos cirurgiões-dentistas na esfera privada}

A primeira seqüência de conteúdos temáticos evidenciados trata, primordialmente, de consignações inerentes aos discursos sobre um percurso que se inicia com as expectativas e motivações da escolha profissiona,; segue com as experiências e algumas frustrações com o curso de graduação em Odontologia e converge para a constatação de desencanto e insustentabilidade quanto ao exercício das atividades profissionais, nos moldes da prática liberal e autônoma, sob as condições atuais do mercado de trabalho.

Nos discursos analisados, houve uma alusão recorrente ao fato de que a escolha profissional deveu-se ao exemplo de pessoas próximas, que já eram cirurgiões-dentistas respeitados e que 
trabalhavam em seus consultórios particulares. Revelou-se uma motivação e expectativa inicial sobre a carreira de cirurgião-dentista, que a considerava como promissora, em termos de estatuto social, de grande autonomia profissional e de ganhos econômicos compensadores.

Já no decorrer do processo de formação na graduação de Odontologia, eram percebidos os primeiros indícios do que alguns entrevistados denominaram de "mercado de trabalho saturado", com referências às situações de excesso de profissionais formados, alta competitividade, subempregos, dificuldades para o trabalho em consultórios particulares etc. Segundo alguns relatos, tais indícios geraram apreensões sobre a inconformidade ou "deficiência" do processo de formação em relação às novas condições e exigências do mercado de trabalho, devido a entendimentos sobre dificuldades estruturais e problemas curriculares presentes no decorrer do curso de graduação. Alguns entrevistados chegaram a relatar situações em que alguns professores negavam-se a ensinar determinados conteúdos disciplinares especializados ou a instruir técnicas específicas, porque não queriam preparar profissionais que, mais tarde, estariam competindo com eles próprios no mercado de trabalho.

Quando você se volta mais para as especialidades, eu acho que não deu um suporte legal não. Agora, é devido os professores não terem empenho legal para ensinar, tipo Ortodontia... eles evitavam passar o conhecimento para a gente. Eu acho que até por medo de perder o mercado deles, sei lá... pronto, é isso aí ! (Entrevistado 1)

Existem várias consignações discursivas sobre uma incongruência entre a orientação dos conteúdos ou práticas do curso de graduação e a realidade encontrada no campo de atividades profissionais e no mercado de trabalho, notadamente no caso da esfera pública. Alguns entrevistados entenderam que tais incongruências eram inevitáveis, cabendo aos próprios estudantes de graduação o esforço pessoal para preparar-se devidamente para a competição por nichos especializados de mercado.

A percepção de incongruências existentes entre o processo de formação na graduação e as exigências do mercado de trabalho geraram, em alguns, as sensações de desapontamento e de "frustração ante o investimento realizado". Denotou-se a "falta de oportunidades e perspectivas de trabalho" na esfera privada, juntamente com a convicção de que a profissão do cirurgião-dentista não era mais valorizada socialmente como antes.

Você gasta muito dinheiro e você sai, você começa a trabalhar e você vê que o seu trabalho teve uma desvalorização enorme. Você não tem aquela importância que você achava que iria achar, né? Nesse lado, eu realmente me decepcionei um pouco, sabe? (Entrevistado 3).

O atual mercado de trabalho odontológico foi percebido como muito competitivo, sobretudo devido ao número, considerado excessivo, de cirurgiões-dentistas formados e em formação. Outro fenômeno aludido referiu-se a uma insuficiência de renda da maior parte da população, que não poderia pagar por serviços odontológicos privados. Tal dificuldade estaria constrangendo significativamente as iniciativas e perspectivas de uma prática odontológica liberal por desembolso direto.

Além de tudo, houve um entendimento de que as exigências de investimento, consumo e dependência de equipamentos e instrumentos tecnológicos para o exercício profissional da Odontologia, na esfera privada, tornaram a prática liberal muito dispendiosa, praticamente insustentável para profissionais em início de carreira. Nesse caso, o tema referido nos discursos era: "tecnificação das práticas odontológicas".

Segundo alguns discursos, ante a impossibilidade do trabalho autônomo exclusivo em consultórios próprios, a alternativa de mercado, na esfera privada, seria o trabalho assalariado em grandes empresas e/ou planos de saúde odontológicos. Tal alternativa implicaria em condição de "sobrecarga e exploração do trabalho", "acúmulo de empregos", "insegurança e instabilidade profissionais", descritos com base na experiência de muitos dos entrevistados. 
Consideradas as constatações sobre as condições do mercado de trabalho, haveria poucas chances de um cirurgião-dentista recém-formado tornar-se exclusivamente o típico profissional liberal, trabalhando em seu próprio consultório. A alternativa do assalariamento na esfera privada acarretaria numa remuneração complementar ao trabalho em consultório próprio, ou inversamente, o consultório seria o complemento ao trabalho assalariado.

As referências ao trabalho assalariado denotaram temas recorrentes: "perda de autonomia", "permanente insegurança", "exploração", "insatisfação", "decepção", "frustração", "desencanto", "pouca perspectiva de crescimento profissional". Tais alusões temáticas foram, por fim, sintetizadas num tema referido por muitos dos entrevistados: "insustentabilidade" de permanência na condição de assalariados na esfera privada.

Para alguns dos entrevistados, a constatação de "insustentabilidade" para a manutenção do trabalho na esfera privada resultou num impasse entendido como uma situação crítica. Crise que, por um lado, poderia implicar na perspectiva de abandono da profissão, opção pouco considerada; e, por outro lado, na perspectiva de buscar alternativas de trabalho assalariado, agora na esfera pública.

Nos casos analisados, o PSF configurou-se, na ocasião, como a oportunidade, única e imediata, de "transição" para o trabalho assalariado na esfera pública, em municípios próximos da capital (local de residência da maior parte dos entrevistados). Os termos de alusão às expectativas no momento dessa transição podem significar a disposição de migração voluntária para a esfera pública e, a partir daí, de experimentação de um novo e promissor modo de vida e trabalho profissionais. Podem significar, também, a disposição de ida para um exílio forçado, assumindo-se um emprego, seguro e provisório, enquanto se aguardava o reingresso na esfera privada, em condições mais vantajosas.

Eu acho o seguinte: o PSF, ele vai dar certo e é a perspectiva da Odontologia do futuro. Então, quer dizer, é uma profissão que eu acho que... no passado, muitas pessoas escolheram pela questão de status, pela questão financeira que era muito boa... a pessoa que fizesse Odontologia há vinte anos atrás, enricava. Hoje você tem que ir muito mais pelo lado da satisfação pessoal, através do exercício profissional. Acho que vivi a transição. Quando me formei, estava no fim, era o final da primeira corrente... e hoje eu estou na segunda. Agora, eu acho que se a pessoa ver só o lado financeiro ela vai ter uma grande decepção, eu acho que já saiu desse paradigma. (Entrevistado 8)

Depois que a gente montou o consultório, foi passando o tempo e eu botei na minha cabeça que não era aquilo que eu queria. Eu queria um trabalho que me desse estabilidade, que tivesse aquele salariozinho todo mês, que eu pudesse contar, que eu pudesse me dividir melhor, trabalhar. Aí fiquei tentando, o meu sonho de consumo era ir para o PSF de XXX (município), todo mundo falava em $X X X$. Só que depois que eu entrei em $X X X$, que fiquei com aquele dinheiro todo mês e tudo o mais, o meu sonho de consumo agora é montar um consultório particular (Entrevistado 1).

Os entrevistados afirmaram que a escolha de trabalhar no PSF era quase sempre constrangida pela insustentabilidade de permanência na esfera privada ou pela busca de alguma remuneração regular e segura, o que, para alguns, influenciaria negativamente a atuação profissional do cirurgião-dentista em seu novo âmbito de trabalho. Muitos afirmaram que, geralmente, não havia um conhecimento prévio sobre os princípios e diretrizes do PSF, em razão de despreparo (deficiência na formação de graduação) ou desinteresse dos próprios cirurgiões-dentistas. Para alguns, tal desconhecimento dificultaria afinidade ou identificação prévias para com as normas e condições de trabalho e exercício profissional no PSF. 


\title{
Temas sobre o processo e as condições de trabalho no âmbito do "Programa Saúde da Família"
}

Uma vez mencionados os temas sobre as motivações e a transição para um novo âmbito e processo de trabalho na esfera pública, os entrevistados discorreram sobre as suas impressões e percepções acerca da nova experiência profissional no PSF. Os principais temas aludidos reportaram ao reconhecimento de uma contradição substancial entre o ideário ou as diretrizes normativas do PSF e as reais condições de sua implantação, implementação e processo de trabalho.

Quando se tratou das percepções sobre o ideário e os propósitos normativos do PSF, observou-se a predominância de referências de conotação mais positiva, identificadas com o ideário do Sistema Único de Saúde (SUS). O PSF foi, então, definido como uma proposta ministerial, como um modelo assistencial generoso, de caráter universal e integral, que tem como foco as famílias e comunidades mais carentes.

É a proposta que veio do Ministério, né? Da universalização, intersetorialidade, integralidade, né? E que há a descentralização dos serviços. Então, quer dizer, esta proposta é interessante e que bate na proposta do SUS... Então, a gente entende mais-ou-menos o que está proposto na parte teórica das coisas, na parte prática não... muda um pouco. (Entrevistado 2).

Quando se tratou das tematizações sobre a experiência pessoal e profissional no PSF, foram reveladas sensações ambíguas: de satisfação pelo contato e proximidade com as comunidades locais, com a gratidão revelada; e de insatisfação com as condições de trabalho.

\begin{abstract}
$\mathrm{Na}$ verdade, tem horas quando a gente faz um trabalho interessante, quando a gente vai para a comunidade, que eles começam a entender isso. Aí você sai um pouco empolgado... puxa, esta é a proposta! Mas tem hora, assim, que a nossa capacidade de atendimento é de vinte pessoas, aí você encontra quarenta, cincoenta pessoas numa fila e eles reclamam... e realmente não podemos atender... e isso acaba abatendo a gente. Então, quer dizer, têm horas que eu me sinto, às vezes tem hora que eu me cobro... O que atrapalha, para mim... é quando você vê uma disputa daquela, achando que você está disputando espaço, que você está ali para fazer marketing. (Entrevistado 2)
\end{abstract}

Tem hora que eu gosto, tem hora que eu não gosto, tem hora que eu me sinto bem de estar lá e tudo o mais... Você é... Na maioria dos casos, eu tenho um retorno muito bom dos pacientes, já ganhei galinha, já ganhei frutas, né? Essas coisas. Sempre o pessoal está lá e tem esse reconhecimento, agradece, dá uma babadinha, diz que gosta do trabalho. Agora tem hora que é um saco você atender vinte pessoas, saber que todo dia você vai se levantar e vai atender vinte pessoas ou mais. (Entrevistado 1)

Os principais motivos de insatisfação com o exercício profissional no PSF referiram-se às suas condições estruturais e organizativas, consideradas insuficientes ou inadequadas pela maior parte dos entrevistados. Notadamente, a falta ou insuficiência de insumos tecnológicos e a ausência ou dificuldade de manutenção sistemática dos equipamentos odontológicos.

No aspecto organizativo da demanda e atendimento dos serviços, preponderou a queixa, já mencionada, da desorganização e do excesso de demanda espontânea. A sobrecarga de demanda espontânea, o trabalho repetitivo e o excesso de atendimentos clínicos, curativos individuais, foram freqüentemente citados como os mais relevantes dos problemas organizativos no PSF, associados, geralmente, ao desgaste pessoal dos cirurgiões-dentistas e ao comprometimento da qualidade de seus serviços.

Outro tema recorrente estava referido às dificuldades de integração no trabalho em equipes do PSF. Uma das diretrizes normativas típicas do PSF é aquela que estabelece o processo de trabalho integrado, interdisciplinar, entre equipes multiprofissionais. Nesse aspecto, todos os entrevistados 
referiram que tal processo de trabalho era pouco integrado, restringindo-se, na maior parte das vezes, ao encaminhamento de casos clínicos entre os membros da equipe. Alguns reiteraram que tal dificuldade de integração deveu-se a uma "tradição" de insulamento profissional dos cirurgiõesdentistas e de suas práticas de trabalho em consultório. Para outros, a imagem dos cirurgiõesdentistas seria mais "estigmatizada", estando ligada às práticas curativas, como extrações e obturações de dente, o que contribuiria para um certo "isolamento" dos cirurgiões-dentistas em relação aos outros profissionais do PSF. Um dos entrevistados ressaltou que a utilização de sistemas de registros específicos e separados dificultaria ainda mais o intercâmbio de informações clínicas e a integração entre as equipes do PSF.

Outro aspecto ressaltado foi o desgaste presente nas relações entre os profissionais de nível superior que atuavam no PSF, inclusive entre os próprios cirurgiões-dentistas, em razão de desconfianças e disputas internas.

Houve uma interpretação de que as diferenças salariais entre os profissionais de nível superior que trabalham conjuntamente no PSF, notadamente entre os médicos e outros profissionais, realçariam as dificuldades de integração no trabalho em equipe e estimulariam atitudes de competitividade, ao invés de cooperação mútua. Foram recorrentes os relatos de incompreensão, inconformidade e desestímulo em relação à diferença de ganhos salariais entre os cirurgiões-dentistas e os médicos e enfermeiros do PSF. Alguns alegaram que as atividades cotidianas do trabalho odontológico no PSF exigiam um desgaste físico e mental equivalente ou maior do que aqueles do trabalho de médicos e enfermeiros.

Houve uma constatação comum de que a baixa remuneração salarial do PSF era um obstáculo para a consolidação do serviço público como um novo nicho de mercado para os cirurgiões-dentistas, o que seria agravado pela forma "precarizada" das contratações por parte dos municípios.

A situação, denominada por alguns dos entrevistados de "precarização do trabalho" estava referida à inexistência ou informalidade de vínculos contratuais entre os cirurgiões-dentistas e os serviços públicos. Devido a tal situação, foram destacadas sensações de insegurança, vulnerabilidade, dependência e constrangimento para a autonomia profissional. Em outros termos, a informalidade na garantia de emprego e de regularidade de um rendimento salarial mensal gerava incertezas sobre o futuro e expunha os cirurgiões-dentistas a uma condição de dependência e vulnerabilidade perante os interesses e a vontade dos contratantes.

Alguns dos entrevistados relataram o que consideraram como "pressões" ou "interferências políticas" em seu processo de trabalho. Esses temas foram descritos como a interposição de autoridade, da parte de dirigentes governamentais (inclusive de dirigentes dos serviços de saúde), no modo de organização e funcionamento dos serviços odontológicos do PSF; notadamente em razão de interesses eleitorais, político-partidários ou da necessidade de propagação de uma imagem positiva da administração pública ante os usuários dos serviços. Em termos práticos, tais "pressões" ou "interferências políticas" implicariam, sobretudo, a determinação, por parte de dirigentes governamentais, de que não houvesse demanda reprimida nos serviços, de que todas as demandas espontâneas e imediatas deveriam ser atendidas, a fim de evitar desgastes ou críticas da chamada "opinião pública". Outro modo de "pressão" ou "interferência" política ensejaria na determinação, mais ou menos sutil, de favorecimento ou privilegiamento na inclusão ou agendamento de determinados usuários, em detrimento dos critérios preestabelecidos para a organização da demanda.

Para alguns dos entrevistados, as referidas "pressões" ou "interferências políticas", assim como as suas decorrências, foram interpretadas como "naturais" e inerentes a qualquer processo de trabalho na esfera pública. Nesses casos, alguns alegaram restringir-se ao "trabalho no consultório", deixando para outrem a definição dos modos do atendimento privilegiado ou diferenciado em função de interesses da "política local". Para outros entrevistados, a mesma situação gerava desgastes, constrangimentos e sobrecarga de trabalho:

Principalmente agora, neste momento (época de eleições municipais), porque eles ficam preocupados com a questão política. A gente tem que fazer a questão política, a gente é convidado a defender o projeto da administração. Esses colegas que não têm vínculo, eles ficam com a preocupação maior... então, pode atrapalhar o serviço. (Entrevistado 2) 
O local de trabalho é um local muito político. Mas sempre, nas minhas atividades, eu procuro ser imparcial, eu procuro sempre ficar o mais longe possível da política, né? (Entrevistado 6).

De acordo com alguns entendimentos da parte dos entrevistados, tais condições de trabalho dificultariam o envolvimento dos cirurgiões-dentistas com iniciativas ou projetos de médio ou longo prazos, uma vez que persistiam as sensações de insegurança, instabilidade e falta de autonomia profissional. A recomendação mais comum: realização de concurso público para a contratação de profissionais no PSF.

Por fim, foi revelada a sensação de frustração ante às expectativas iniciais, mesmo que comedidas, que versavam sobre as idealizações da norma PSF e as novas possibilidades de trabalho e exercício profissional na esfera pública. O PSF foi, então, consignado como um ideal generoso, mas contraditório, sendo uma alternativa também insegura para os cirurgióes-dentistas. Ressaltou-se a persistência da sobrecarga de trabalho, ausência de suporte tecnológico adequado, baixa remuneração, competitividade e dos constrangimentos da autonomia profissional, temas já referidos sobre o processo de trabalho na esfera privada.

É claro que, diante da complexidade dos contextos discursivos e de contradições inerentes aos mesmos, a descrição sucinta de alguns temas evidenciados com base em discursos práticos sobre os processos de trabalho de cirurgiões-dentistas não é suficiente para caracterizar perfis de opiniões. Antes, trata-se tão-somente de alguns de seus indícios, que podem ser analisados na medida da pretensão exploratória anunciada.

Em certa medida, as tematizações sobre as experiências de trabalho e prática profissional dos cirurgiões-dentistas evidenciaram ciclos recorrentes (Figura 1), que se iniciaram a partir de expectativas (mesmo que comedidas) e convergiram para a revelação de desencanto e frustração perante as condições reais de trabalho e de prática profissional nas esferas privada e pública.

\begin{tabular}{|c|c|c|c|c|c|}
\hline \multicolumn{2}{|c|}{$\begin{array}{c}\text { Atividades profissionais } \\
\text { e mercado de trabalho } \\
\text { na esfera privada }\end{array}$} & oportunidade & $\underset{\text { migração voluntária }}{\stackrel{\text { voluntário e temporário }}{\longrightarrow}}$ & \multicolumn{2}{|c|}{$\begin{array}{c}\text { Atividades profissionais } \\
\text { e mercado de trabalho } \\
\text { na esfera pública }\end{array}$} \\
\hline & $\begin{array}{l}\text { Insustentabili } \\
\text { Desencanto } \\
\text { Investimento } \\
\text { Pouca perspe } \\
\text { Insatisfação c } \\
\text { Exploração do } \\
\text { Acumulação } \\
\text { Trabalho des\& } \\
\text { Baixo poder a } \\
\text { Excessiva "te } \\
\text { Excesso de pr } \\
\text { no mercado } \\
\text { Formação def } \\
\text { Escolha profis } \\
\text { de prática lib }\end{array}$ & $\begin{array}{l}\text { essoal frustrado } \\
\text { iva de crescimento profissional } \\
\mathrm{m} \text { as condições de trabalho } \\
\text { trabalho assalariado } \\
\text { empregos } \\
\text { stante } \\
\text { uisitivo da clientela } \\
\text { ificação" das práticas } \\
\text { fissionais e "saturação" }\end{array}$ & $\begin{array}{r}\text { Satisfação em ajud } \\
\text { Insatisfação com as cond } \\
\text { Suporte téc } \\
\text { Excesso de dem } \\
\text { Trab } \\
\text { Ba } \\
\text { Ausência de vínc } \\
\text { Trabalho desintegrado na } \\
\text { "Interferências pol }\end{array}$ & $\begin{array}{l}\text { lotação positiva } \\
\text { prática no PSF } \\
\text { Ambigüidade } \\
\text { r a comunidade } \\
\text { ões de trabalho } \\
\text { icco inadequado } \\
\text { nda espontânea } \\
\text { lho desgastante } \\
\text { a remuneração } \\
\text { lo empregatício } \\
\text { Instabilidade } \\
\text { Insegurança } \\
\text { equipes do PSF } \\
\text { ico-partidárias" } \\
\text { Frustração }\end{array}$ & $\begin{array}{l}\text { âmbito do } \\
\text { Programa } \\
\text { Saúde da } \\
\text { Família (PS } \\
\text { equipes de } \\
\text { Saúde buca }\end{array}$ \\
\hline \multicolumn{2}{|c|}{$\begin{array}{l}\text { Identidade e perfil } \\
\text { de profissional liberal } \\
\text { ou de assalariado }\end{array}$} & $\begin{array}{r}---------- \\
\text { crise e busca de ident }\end{array}$ & idade profissional & \multicolumn{2}{|c|}{$\begin{array}{c}\text { Perfil de assalariado do } \\
\text { serviço público sem vínculo } \\
\text { empregatício formal }\end{array}$} \\
\hline
\end{tabular}

Figura 1. Descrição de conteúdos temáticos com referências aos âmbitos e esferas de atuação, mercado de trabalho e atividades profissionais doscirurgiões-dentistas entrevistados. 


\section{Discussão}

A interpretação dos diversos conteúdos temáticos consignados nos discursos práticos dos entrevistados carece de um contexto discursivo mais abrangente, a hermenêutica de um sentido mais amplo para as diversas contradições reveladas. Nas tematizações sobre os processos de trabalho em ambas as esferas (privada e pública), são reveladas sensações e percepções de frustração, insatisfação, insegurança, ambigüidade. Inicialmente, a medida subjetiva para o juízo de tais significações são as expectativas de todos e de cada um, seja no momento da escolha profissional e formação de graduação, seja de ingresso ou transição no mercado de trabalho. Expectativas que, quando compartilhadas em um "senso prático comum", podem ser consideradas como elementos constituintes do habitus profissional desses cirurgiões-dentistas.

O habitus dos cirurgiões-dentistas, constituído historicamente a partir de um campo profissional de ideologia e práticas liberais, está em pleno processo de mudança, especialmente no que se refere às mudanças de posições e disposições dos profissionais no processo de trabalho (do profissionalismo liberal para o assalariamento). O que pode implicar crise existencial do referido habitus; seja no significado do termo "crise", pela junção dos ideogramas mandarins (perigo + oportunidade), seja pelo significado da língua portuguesa de ruptura, divisão, descontinuidade e purificação (Boff, 2002).

Crises de descontinuidade decorrentes de transformações e adaptações, mais lentas ou mais rápidas, engendram contradições substanciais entre as razões e os modos de ser das instituições formadoras, das corporações profissionais e do mercado de trabalho, nas esferas pública e privada. As novas determinações e condições de formação social (Marx, 1984), especificamente do mercado de trabalho na esfera privada, estão destituindo o capital simbólico e constrangendo as margens de autonomia do habitus profissional dos cirurgiões-dentistas, centrado no ideário liberal clássico; suplantando-o e constituindo um novo habitus referenciado pelo trabalho assalariado e serial, por novos padrões de competitividade e de intermediação tecnológica.

As instituições formadoras não operam com a mesma velocidade do mercado, seus modos de readaptação são mais graduais, embora, por razões desse mercado, tendam a expandir a oferta de cursos e vagas aumentando, assim, o volume de mão-de-obra disponível para o novo mercado, o novo liberalismo, mas contraditoriamente, ainda sob a égide da ideologia liberal da profissão, do habitus que se extingue. A expectativa frustrada ante um processo de formação que não prepara o cirurgião-dentista para a nova realidade de mercado pode, em certa medida, resultar num embotamento provocado pelo cultivo de uma ideologia tecnocrática nas práticas de ensino e aprendizado na graduação.

Em termos gerais, a ideologia tecnocrática tem como função obstruir, interditar a abertura dos discursos práticos e impedir a tematização sobre os fundamentos do poder. Algumas normas institucionais, por exemplo, podem ser objeto de pseudo-legitimação quando cumprem a dupla função de impedir que elas próprias e seus propósitos sejam tematizados discursivamente. Nesse particular, busca-se substituir as normas sociais por regras técnicas. Se os fundamentos do poder não precisam ser tematizados, "não é porque repousam sobre a normatividade legítima, mas porque a lógica das coisas passa a ser preponderante" (Freitag \& Rouanet, 1993, p.16). Assim, tornam-se necessários os investimentos, em termos de gestão do trabalho, na abertura de espaços da esfera pública para a tematização sobre as relações de poder e práticas profissionais.

Em sua maior parte, os cursos de graduação em Odontologia no país possuem currículos orientados para uma formação mais técnica, com uma prática clínica individualizada, fragmentada, biocêntrica, curativa, com ênfase no uso de tecnologias "de ponta" (Narvai, 2003). Salienta-se, assim, a preponderância de um "racionalismo cartesiano disjuntivo" que, além de dar ênfase aos domínios cognitivos e instrumentais da formação, faz uma separação, por oposição, das esferas público-estatal e privada como pólos repelentes gerando, dessa forma, uma ruptura, tanto na organização objetiva do sistema, quanto nas estruturas mais profundas, em que as práticas sociais são representadas (Moysés, 2004).

Alguns autores, como Zanetti (2001), criticam a unidimensionalidade tecnológica preponderante no desenvolvimento do perfil de habilidades nos cursos de graduação em Odontologia, quando 
mesmo as pretensões de enfoque ampliado tratam de um "sujeito coletivo" indeterminado e descontextualizado. Para esses autores, trata-se de uma redução que desconsidera o desenvolvimento de habilidades em outras áreas substanciais, como administração, marketing e, sobretudo, na dimensão das relações interpessoais.

Tal redução de foco produz um condicionamento de habitus que tende a valorizar o domínio e o uso de uma racionalidade instrumental na prática clínica; em certa medida, condizente com a reificação produzida na ideologia liberal de mercado. Habilidades e competências individuais em biotecnologia, apropriadas para produzir procedimentos clínicos com valor de consumo, mas, notadamente, com valor de troca no mercado. Livre iniciativa e autonomia para organizar serviços privados, sustentados pelo desembolso direto ou indireto da clientela, com competência e habilidade de competição no mercado de oportunidades. Razão teleológica, cuja ideologia é hegemônica nas sociedades contemporâneas, reduzindo a produção ao ato funcional de produzir bens de consumo para fazer o mercado girar (Campos, 2000).

Como afirmado anteriormente, a escassez de oportunidades vantajosas no mercado de trabalho induz ou impõe a escolha de novas oportunidades de trabalho na esfera pública emergente. O PSF torna-se, então, uma espécie de "tábua de salvação", num mar de frustrações. Pode ser a oportunidade de "emprego", mas não necessariamente de "realização profissional". Pode levar a um abrigo provisório ou a um "porto seguro", a depender de sua capacidade de re-condicionar o senso prático comum. Alguns optam pela migração voluntária para o trabalho na esfera pública, redimensionando as suas expectativas ao reconhecer o PSF como a melhor perspectiva de trabalho assalariado.

As percepções evidenciadas sobre as experiências no novo ambiente de trabalho e na implementação da estratégia programática (Saúde Bucal no PSF) denotam outras contradições entre as normas institucionais e a realidade de sua implementação: entre as proposições normativas do programa e as condições objetivas de sua implementação, entre as proposições normativas da boa atuação profissional e as condições práticas de seu exercício; como, também, contradições entre o processo instituinte e a cultura organizacional instituída.

As mudanças percebidas no re-condicionamento deste senso prático comum, no habitus profissional, revelam algumas tentativas de adaptação comportamental ao novo contexto organizacional, algo intermediário entre o instituinte e o instituído. Em alguns casos, de alienação, negação de envolvimento mais íntimo com o processo em curso, seja por desinteresse genuíno ou pela vulnerabilidade perante ameaças ou riscos pressentidos, velados ou explícitos (como o desemprego).

Senso prático de adaptação e/ou alienação que induz a uma predominância de comportamentos regrados (Weber, 1996). Comportamentos orientados por interesses, como, por exemplo, nos posicionamentos frente aos interesses político-eleitorais locais em jogo; orientados por valores, especialmente pelas disposições nos serviços públicos condicionadas com base nos valores constituídos desde a formação na graduação; comportamentos determinados pela tradição da prática profissional liberal.

São muitos os fatores que limitam a capacidade desses profissionais de inovar suas práticas de trabalho em um novo contexto organizacional. O senso prático comum, quando auto-referenciado, estabelece uma tendência de acomodação e alienação, determina a preponderância de comportamentos tradicionais.

Uma das características primordiais dos comportamentos tradicionais, pelo menos em processos instituintes dessa natureza, é a dificuldade ou incapacidade de lidar com inovações, o que pode levar ao comprometimento e à desintegração de identidade, ao insulamento ou acomodação. Trabalhadores com baixa auto-estima, acomodados às situações que impossibilitam o exercício efetivo da clínica, passando a trabalhar de forma mecânica, sob a vigilância controladora ou por causa dos estímulos econômicos (Campos, 2002).

O insulamento corporativo tende a definir os seus domínios no ambiente do consultório odontológico, nicho de seu poder técnico. Se o domínio de conhecimentos clínicos e as habilidades adquiridas para a realização de procedimentos técnicos podem ter grande valia no espaço protegido dos consultórios, auxiliam pouco na conquista de espaços e prerrogativas de poder (político, técnico) 
ante as equipes preexistentes no PSF. Seu carisma institucionalizado, capital simbólico tão caro na prática liberal, não pode ser convertido em prestígio e nem disponibilizado no jogo de posições e disposições do novo campo multiprofissional, interdisciplinar. Seus ganhos salariais, quando comparados, reforçam a sensação de desprestígio ante os outros profissionais da equipe.

Em razão disso, o novo campo de atuação profissional exige o domínio de conhecimentos e de habilidades para lidar com uma dialética de cooperação e competição em ambientes institucionais da esfera pública, na qual se tende a valorizar a interação e o trabalho interdisciplinar, exigindo, dessa forma, além de comportamentos regrados ou ações intencionais normativas e instrumentais, o desenvolvimento e exercício de ações estratégicas e comunicativas (Habermas, 1987).

\section{Conclusão}

Os cirurgiões-dentistas entrevistados revelam algumas frustrações quanto às suas aspirações profissionais, sobretudo em razão de perceberem incompatibilidades entre as suas motivações e expectativas iniciais de escolha profissional e as condições inadequadas de seu processo de formação na graduação, a saturação do mercado para a prática liberal, a insatisfação com as condições encontradas para a prática de trabalho na esfera pública, no âmbito da Atenção Básica à Saúde, especificamente em serviços do PSF.

Em suma, denota-se uma crise decorrente da mudança de habitus profissional dos cirurgiõesdentistas, em função de sua inserção em um novo contexto de trabalho assalariado e da prestação de serviços na esfera pública, diverso da expectativa e ideação iniciais de uma atuação profissional liberal. Nas consignações analisadas não há, ainda, evidências da apropriação de um novo habitus de profissional assalariado, mas de sinais e sintomas contraditórios sobre os desgastes ou a perda da aura do habitus de profissional liberal.

Revelam-se, ainda, algumas incompatibilidades entre os propósitos normativos do PSF e as condições objetivas para o exercício da prática profissional em Odontologia. Também são identificadas tendências de adaptação ou alienação diante do novo contexto de formação social sem, contudo, realizar uma tematização explícita sobre os fundamentos e tensionamentos de poder no âmbito institucional.

Sugere-se, por fim, a realização de outros estudos de abordagem qualitativa, que possam analisar as representações sociais e opiniões dos cirurgiões-dentistas sobre o processo e práticas de trabalho. 


\section{Referências}

BARDIN, L. Análise de conteúdo. Lisboa: Edições 70, 1977.

BOFF, L. Crise, oportunidade de crescimento. Campinas: Verus, 2002.

BOURDIEU, P. Razões práticas: sobre a teoria da ação. Campinas: Papirus, 1996.

BRASIL. Ministério da Saúde. Secretaria de Atenção à Saúde. Departamento de Atenção Básica. Números, 2006. Disponível em: <http://dtr2004.saude.gov.br/dab/ atencaobasica.php\#historico>. Acesso em: 13 abr. 2007.

Fundação Oswaldo Cruz. Saúde da família: avaliação da implementação em dez grandes centros urbanos: síntese dos principais resultados. 2.ed. Projetos, Programas e Relatórios. Brasília: Ministério da Saúde, 2005. (Série C).

Conselho Nacional de Saúde. Comissão Nacional de Ética em Pesquisa. Normas para pesquisa envolvendo seres humanos. 2.ed. Brasília: Ministério da Saúde, 2003.

CAMPOS, G.W.S. Um método para análise e co-gestão de coletivos: a constituição do sujeito, a produção de valor de uso e a democracia em instituições: o método da roda. São Paulo: Hucitec, 2000.

Subjetividade e administração de pessoal: considerações sobre modo de gerenciar trabalho em equipes de saúde. In: MERHY, E.E.; ONOKO, R. (Orgs.). Agir em saúde: um desafio para o público. 2.ed. São Paulo: Hucitec, 2002. p.229-66.

COSTA, I.C.C.; SALIBA, O.; MOREIRA, A.S.P. Atenção odontológica à gestante na concepção médico-dentista-paciente: representações sociais dessa interação. RPG Revista de Pós-Graduação, v.9, n.3, p.232-43, 2002.

FREITAG, B.; ROUANET, S. P. Habermas. 3.ed. São Paulo: Ática, 1993.

GIRARDI, S.N.; CARVALHO, C.L. Configuração do mercado de trabalho dos assalariados em saúde no Brasil. Disponível em: <http://www.opas.org.br/rh>. Acesso em: 6 dez. 2004.

HABERMAS, J. Teoria da la acción comunicativa. Madri: Taurus Humanidades, 1987.

MARX, K. O capital: crítica da economia política. São Paulo: Abril Cultural, 1984. (Coleção Os Economistas, v.1-3).

MELLIN, A.S; TANAKA, O.Y. Representações sociais dos profissionais de um centro de saúde em seu cotidiano e suas práticas. Rev. Ciênc. Méd., v.12, n.1, p.25-38, 2003.

MINAYO, M.C.S. O desafio do conhecimento: pesquisa qualitativa em saúde. 4.ed. São Paulo/Rio de Janeiro: Hucitec/Abrasco, 1996.

Hermenêutica-dialética como caminho do pensamento social. In: MINAYO, M.C.S.; DESLANDES, S.F. (Orgs.). Caminhos do pensamento, epistemologia e método. Rio de Janeiro: Editora Fiocruz, 2002. p.83-107.

MOREIRA, T.P.; NUTO, S.A.S.; NATIONS, M. K. Confrontação cultural entre cirurgiõesdentistas e a experiência de usuários de baixa renda em Fortaleza, Ceará. Saúde Debate, v.28, n.66, p.58-67, 2004.

MOYSES, S.J. Política de saúde e formação de recursos humanos em odontologia. Rev. ABENO, v.1, n.4, p.30-7, 2004. 
NARVAI, P.C. Recursos humanos para promoção da saúde bucal: um olhar no início do século XXI. In: KRIGER, L. (Coord.). ABOPREV. 3.ed. São Paulo: Artes Médicas, 2003. p.475-94.

PEREIRA, D.Q.; PEREIRA, J.C.M.; ASSIS, M.M.A. A prática odontológica em Unidades Básicas de Saúde em Feira de Santana (BA) no processo de municipalização da saúde: individual, curativa, autônoma e tecnicista. Ciênc. Saúde Coletiva, v.8, n.2, p.599-609, 2003.

RODRIGUES, M.P; DOMINGOS SOBRINHO, M.; SILVA, E.M. Os cirurgiões-dentistas e as representações sociais da Aids. Ciênc. Saúde Coletiva, v.10, n.2, p.463-72, 2005.

Cirurgiões-dentistas e representações sociais da biossegurança. In:

FERNANDES, A.; CARVALHO, M.R.; DOMINGOS SOBRINHO, M. (Orgs.).

Representações sociais e saúde: construindo novos diálogos. Campina Grande: EDUEPB, 2004. p.247-73.

WEBER, M. Economia e sociedade. 3.ed. Brasília: Ed. Universidade de Brasília, 1996. v.1.

ZANETTI, C.H.G. Opinião: a inclusão da saúde bucal nos PACS/PSF e as novas possibilidades de avanços no SUS. 2001. Disponível em: < http://www. saúdebucalcoletiva.unb.br>. Acesso em: 26 nov. 2004.

CHAVES, M.C.; MIRANDA, A.S. Discursos de cirujanos-dentistas del Programa Salud de la Familia brasileño: crisis y cambio de habitus en la Salud Publica. Interface - Comunic., Saúde, Educ., v.12, n.24, p.153-67, jan./mar. 2008.

En el artículo se analizan los significados de discursos proferidos por cirujanos-dentistas que tratan de las percepciones sobre la propia inserción y actuación profesionales en los servicios del Programa de Salud de la Familia de municipios del área metropolitana de Fortaleza, estado de Ceará, Brasil. Se trata de un estudio cualitativo basado en entrevistas con informantes-clave, empleando una técnica derivada del método de "Análisis de Contenido" y aproximación dialéctica. Los contenidos temáticos colocan en evidencia la percepción de contradicciones entre las motivaciones y expectativas iniciales de elección e identificación profesionales; las ideaciones sobre la actuación profesional; el proceso de formación en la graduación; y las condiciones reales de inserción, actuación profesional y prácticas de trabajo en servicios públicos de la Atención Básica a la Salud en Brasil. Se percibe la crisis de un determinado habitus profesional, en razón de su inserción en un nuevo contexto de trabajo asalariado y prestación de servicios en la esfera pública diferentes de la expectativa e ideación iniciales de una actuación profesional- liberal.

Palabras clave: Percepción social. Práctica profesional. Odontología comunitaria. Educación en odontología. Salud familiar. 